\title{
Brief 37: Pascual Jordan an Grete Hermann (27.2.1937)
}

Physikalisches Institut Seestadt Rostock

Blücherplatz den 27.2.37

Fernruf 7081, Nebenstelle 252-254

Fräulein Dr. Hermann,

Bremen

Moselstr. 26

Sehr verehrte Fräulein Hermann!

Die angenehme Pflicht, Ihnen zu danken ${ }^{1}$ für die freundliche Zusendung des Sonderdruckes Ihrer neuen schönen Arbeit[,] gibt mir willkommene Gelegenheit, noch einmal zurückzukommen auf unsere mündliche Unterhaltung in Kopenhagen.

Ich habe damals in der Eile nicht recht zum Ausdruck bringen können, dass ich abgesehen von dem die Neumannsche Beweisführung betreffenden Punkte, den wir etwas verschieden ansahen - Ihre damalige Arbeit mit ungeteilter Freude und Zustimmung gelesen habe.

Mit vielen verbindlichen Empfehlungen bin ich

Ihr sehr ergebener

P. Jordan

NB. Könnten Sie vielleicht so freundlich sein, mir die Ihnen vermutlich bekannte Anschrift von Dr. Th. Vogel in Bad Nauheim mitzuteilen? Besten Dank im Voraus.

1 Im Original „dankend,“

(C) Springer Fachmedien Wiesbaden GmbH, ein Teil von Springer Nature 2019

K. Herrmann (Hrsg.), Grete Henry-Hermann: Philosophie - Mathematik-

Quantenmechanik, Frauen in Philosophie und Wissenschaft. Women

Philosophers and Scientists, https://doi.org/10.1007/978-3-658-16241-2_59 